\title{
Dentists honoured by the BDA in an exceptionally tough year
}

Sixteen individuals are being celebrated in the latest round of the BDA Honours and Awards, for their outstanding achievements, their commitment to the British Dental Association (BDA) and their work for the dental profession.

Roz McMullan, Chair of the BDA's

Honours and Awards Committee, said: 'It is fantastic to see such a wide range of dentists nominated for our Awards this year. The COVID-19 pandemic has impacted right across dentistry and we know this has been an exceptionally tough year for everyone, so we feel it is just as important as ever that we recognise those who have gone the extra mile for dentistry.

'We know so many members, and not just those with official roles at the BDA, have given long hours and expert knowledge during the pandemic, and we are keen to ensure their achievements and efforts are acknowledged.

'During 2021, we want to find dentists who have shown a commitment to advancing dentistry. We strongly encourage nominations from all areas of the profession - please consider putting forward a colleague/s who you think deserve recognition for what they do.

You can find out more and nominate via www.bda.org/honoursawards.

The deadline for the next round of nominations is 28 May 2021.

\section{Fellowship}

Eddie Crouch has been a GDP for many years and was a partner in a mixed NHS practice in Birmingham, serving a wide section of the community. He is currently Chair of the BDA's Board and has been involved with his branch for over 20 years. As an elected member of the General Dental Practice Committee (GDPC), he has given evidence to Health Select Committees and made the case for pay uplifts to the Doctors' and Dentists' Review Body (DDRB). Eddie has been a consistently strong voice for dentistry, appearing on national and local radio, particularly through the coronavirus pandemic, voicing dentists' concerns.

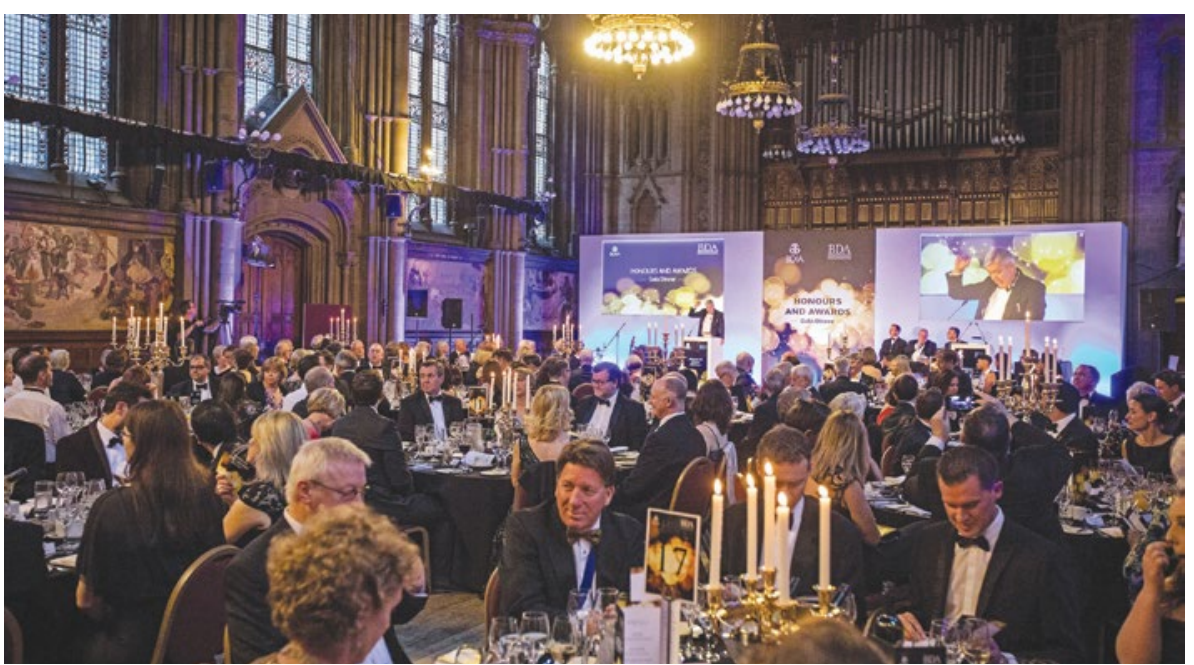

The BDA Honours \& Awards dinner in 2017 held at Manchester Town Hall

Martin Fulford was a renowned lecturer on cross-infection control in dental practice and gave over 100 lectures across the UK, helping to support dentists to provide the highest levels of health and safety in their practices. He published over 30 articles on the subject, including the guidance Infection control in primary dental care, published in 2020. He contributed to the Department of Health's Working Group on HTM 01-05. A long-time supporter of the BDA, Martin was actively involved as a representative, including serving as Treasurer of the Western Counties Branch. He was a member of the BDA's former Representative Body and a valued member of the Health \& Science Committee. Martin sadly passed away in 2020, and the BDA hopes this award will help to recognise his achievements and keep his memory alive.

Jonathan Randall has been an active supporter of the BDA over his extensive career in dentistry. He has been a representative on the GDPC for many years, as well as being involved at his local LDC and BDA branch, and chaired the LDC Conference in 2015. He has been described by others as being totally committed to supporting younger dentists in their future careers, highlighting the key role they will play in ensuring the BDA remains vibrant, dynamic, influential and relevant. He takes an active role in dental politics and has met with local MPs, as well as other stakeholders, to represent dentistry. A keen sportsman, Jonathan has done several walks and bicycle rides raising funds for charities to support his community.

Peter Ward was Chief Executive of the BDA for 14 years, following his career as a dentist. In his role at the BDA, he delivered significant developments, such as the implementation of both a new membership structure and new governance arrangements, and oversaw the creation and rollout of the BDA's Indemnity product. Prior to joining the BDA, he was involved at his local BDA Section and he strove to constantly remind dentists, and those with an influence in dentistry, of their professional standing in the community. His mentoring skills have helped develop 'deep-thinking' dentists and staff, which has been invaluable to many of our elected officers and representatives.

\section{John Tomes}

Trevor Burke is one of the UK's most wellrespected and popular clinical academics. $\mathrm{He}$ is a sought-after lecturer, both nationally and internationally, and is famous for his hugely entertaining, evidence-based lectures and hands-on training courses. Trevor brought 20 years of experience in general dental practice to his remarkable academic career, via Manchester, Glasgow and Birmingham dental schools. His almost 
4 unprecedented 370+ peer-reviewed papers and textbooks are entirely focused on subjects relevant to clinical practice in primary care, where he also founded the UK's leading practice-based research network. Trevor is a massively influential teacher, editorial director, researcher and examiner from undergraduate to $\mathrm{PhD}$ level, and has supervised many of the research projects carried out by the students enrolled on one of the country's longest-running Master's programmes at the University of Birmingham. Alongside his career as a university educator, Trevor acts as a friend, mentor and advisor to countless clinicians throughout the UK and around the world, and he is a key opinion leader for most global dental manufacturing companies.

\section{Life Membership}

Jude Anderson is a well-respected community dentist who has given her skill and dedication to dentistry for many years. She has long been involved with the BDA, including serving on the Northern Ireland Salaried Dentist Committee (NISDC) and the GMC's Community Dental Service (CDS), as a postgraduate member. As President of the NISDC in 2018, she oversaw a sold-out conference and won an award from the North West Business Community for this event. Now retired, Jude continues to lend her support to the Committee, helping colleagues through the COVID-19 pandemic, and plans to chair the CDS Group session at the British Dental Conference and Dentistry Show in May.

Bridget Ashton has been a lifelong member of the BDA and, while she was a member of the Plymouth Section, became the first female section Chair in 1996, as well as serving as section Treasurer for 20 years. In 2009, Bridget deservingly received the Certificate of Merit for services to the profession and in 2017 became Branch President for two years. For the past five years, she has been the Branch's Benevolent Fund Secretary and intends to continue in this role after her retirement. Alongside this, Bridget has been instrumental in enabling the younger members of the profession to establish the Young Dentists Group in the South West.

John Glen has always been active in the East of Scotland Branch, working as a GDP for over 30 years. He has served the Branch continuously both as a Branch
Council member and as a member of the Scottish Dental Practice Committee (SPDC) from 1998-2019 and the SDPC Executive Committee 2008-2019. He has served twice on the BDA Scottish Council and was instrumental in the creation of a Young Dentists Group in the East of Scotland Branch. During his career, he always had a professional interest in children's dentistry and was a member of two guidance development groups for SIGN and SDCEP.

Gill Greenwood has been a member of the BDA for over 30 years and was nominated for her substantial contribution to dentistry and the Community Dental Services (CDS) Group. She took over as Chair of the BDA's CDS GMC for six years, ending in 2018, working tirelessly to promote the Group's work. This was closely followed by her Presidency in 2019 and she oversaw a very successful Presidential Conference in York in 2019. Gill agreed to extend her Presidential year to ensure she can restart her visits to divisional events and represent the BDA as the CDS Group President for a further year due to the COVID-19 pandemic. She held the post of inaugural Training Programme Director for special care dentistry for Health Education England (HEE) Yorkshire and the Humber for nine years from 2010, and was responsible for setting up and developing their training programme. Gill has always shown support and encouragement for all our members.

Pam Norman worked as a GDP since qualifying in 1979 and has given many years of support to the South Wales Branch, holding many roles on the committee, and is currently acting Chair, even though she has now retired. Her personable, approachable manner and genuine love of people has enabled her to encourage younger members to get involved. She has long been involved with the BDA's Benevolent Fund and has represented and fundraised for the charity, and is also active in her local community. She is also a Company Secretary of Lifeflight, a charity set up to start an air ambulance service in Swansea.

Neil Oastler is a very modest, hardworking hospital and community dentist who has been ever-present in the oral surgery department of the John Radcliffe Hospital, Oxfordshire's Community Dental Service and its LDC for many years. Neil has arranged the annual Oxfordshire LDC AGM and study day for the last ten years and secured many well-renowned speakers. His enthusiasm in treating anxious patients and his involvement within special care dentistry has enabled community dentistry to continue to provide an effective service despite ever-continuing under-pressure NHS resources. During the COVID-19 pandemic, Neil was instrumental in establishing the first Urgent Dental Care centre hub in South East England, providing much-needed emergency care for patients during this time.

Ivan Simmonds has been involved with the BDA throughout his long career as a dentist. He began as a GDP in London and then moved to Leeds, taking on his own practice in 1975. He worked as a Dental Practice Adviser to Calderdale and Kirklees Health Authority and later PCT from 20012010, advising on clinical governance and practice inspections. He has served in almost all of the offices of the BDA's Leeds and District Section (now the West Yorkshire Section), including Chair, guiding the local committee. He also served as President of the Yorkshire Branch in 1996-1997. He has given unstinting service to the profession, the BDA, and to his colleagues and patients, and in his eightieth year, continues to take an active role, including being an almoner for the BDA's Benevolent Fund since 1990.

Damien Walmsley has been a lifelong member, advocate and supporter of the BDA. His role as the BDA's Scientific Advisor since 2008 and as a clinical academic representative has been of enormous value to the BDA and to the profession. As BDA Scientific Advisor, he has appeared in both national and local press, discussing the science behind dentistry and ensuring the public are better informed. He graduated in dentistry in 1981 and moved to Birmingham in 1985 to teach and research in Prosthodontics and Restorative Dentistry. He became Senior Lecturer, 1991, Consultant, 1993 and Professor, 2000 at the University of Birmingham and has held the posts of Director of Internationalisation (university level) and Head of the Teaching Unit of Prosthetic Dentistry. He is the author of many textbooks and scientific peer-reviewed articles, and as an excellent communicator, he is always keen to share his knowledge and further the profession's learning, especially in the field of IT and social media.

Brian Williams has been an outstanding volunteer for the BDA's Museum, following a long and successful career in dentistry 
4 as a hospital dentist and a GDP. He has been the primary contact for family history research enquiries from the public, helping to make the BDA's Museum archive accessible to all and generating much-needed income. As an excellent communicator and speaker, he has delivered tours of the Museum to adults, children, foundation dentists and dental practice visitors, always garnering excellent feedback. He has represented the Museum at the BDA's annual conferences, at the All-Party Parliamentary Group for Dentistry and Oral Health meetings, and many other events. He has taken an active role in building up the McLean Oral History Archive, interviewing dentists and dental care professionals. He has been Honorary Secretary of the Lindsay Society for the History of Dentistry since 2009. Brian's dedicated work and wonderful sense of humour have been invaluable in helping the BDA's Museum continue its popularity and success.

\section{Certificate of Merit for Services to the} Profession

Shareena Ilyas qualified in 1998 and is currently a GDP working as an associate in a mixed NHS practice in London. She was elected to the BDA's Board in April 2020, the first Asian woman to sit on our Board since its inception. She has since taken on the roles of Chair of the BDA's Education Ethics and the Dental Working Group and is co-Chair of the BDA's newly formed Equality, Inclusion and Diversity Committee. Shareena has always been active at a local level, taking part in her Branch and LDC activities and encouraging younger members to get more engaged in dental politics, as well as representing dentists at a national level. She is passionate about supporting peers and since 2018 has worked with HEE Oxford as a coach/mentor for dentists in difficulty. She is a Trustee of the charity, The Sterling Dental Group, and has raised almost $£ 100,000$ for Great Ormond Street, the India Association (Bobby's Walk) and Ataxia charities.

\section{Roll of Distinction}

Ian Morley's long career at the BDA began in 1992 as a Legal Advisor. He later took on the role as the BDA's first HR Manager in 2001, and devised many of the BDA's policies and procedures, enabling the organisation to ensure transparent, equitable and consultative processes. Ian became Head of HR and Governance in 2004, helping to revise the BDA's Articles of Association in 2012-2013, which saw the representative structure of the BDA change fundamentally - moving away from an Executive Board and Representative Body format to the BDA's current Principal Executive Committee, various Standing Committees, and Country and UK Council structure. Ian then took on the role of Head of Corporate Governance from 2018 until 2020. Ian has been a fundamental part of the fabric of the BDA over such a long period of time, providing much wise counsel for colleagues and elected representatives alike.

\section{Awards ceremonies for 2021}

Unfortunately, because of the pandemic, there has been a delay in the presentation of the 2019 Awards to recipients due to the ongoing restrictions. The BDA hopes to be able to offer an Awards presentation for last year's awardees, as well as a ceremony for the 2020 recipients during 2021, and will keep members updated on developments.

\section{FGDP marks 15 years of raising standards in implant dentistry}

The Faculty of General Dental Practice UK (FGDP) is celebrating the fifteenth anniversary of Training standards in implant dentistry, its publication which defines the training that should be undertaken to carry out implant dentistry safely.

Training standards in implant dentistry is available from a variety of providers including the Faculty, which has trained over 700 dentists through its respected postgraduate diploma course - and this publication sets the standards which UK training courses should meet.

Available free of charge at https://www. fgdp.org.uk/guidance-standards, the document also serves as a reference point for the General Dental Council in the consideration of patient complaints against dentists who have allegedly practised implant dentistry in the UK without the necessary competence.

A review published in 2018 concluded that the development of Training standards

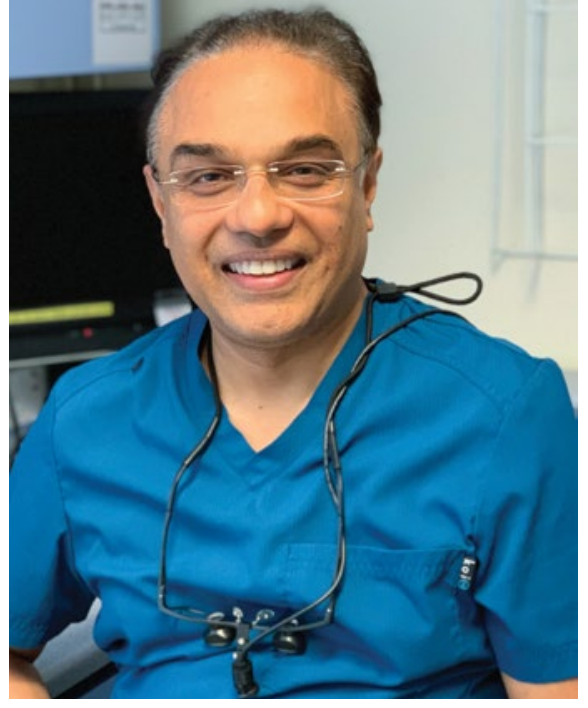

in implant dentistry had 'led to a significant improvement in the quality of postgraduate education in dental implantology in the UK. ${ }^{1}$

However, the review also concluded that 'the provision of mentoring for implant placements needs to be standardised', and the Faculty is currently working with the Association of Dental Implantology to set out more detailed mentoring requirements, which are expected to be published as an appendix to the current guidance in 2021.

Abhi Pal, Editor of Training standards in implant dentistry and Chair of the Faculty's Professional Affairs Committee (pictured), said: 'Developed to standardise and improve training in implant dentistry, Training standards in implant dentistry ultimately helps give patients the confidence they need to seek appropriate treatment. The anniversary of its publication is a moment to celebrate the high standards of training and practice which it underpins, and which dental patients in the UK have been benefiting from for the last 15 years'.

\section{Reference}

1. $\operatorname{Kim} N$ Y, Stagnell S. Postgraduate education in dental implantology in the United Kingdom: a review. Int J Implant Dent 2018; 4: 8. https://doi. org/10.1186/s40729-017-0115-1. 